\title{
Correlation of Insulin-like Growth Factor 1 Receptor Expression With Different Molecular Subtypes of Breast Cancer in the UAE
}

\author{
NOURA ALKHAYYAL ${ }^{1,2,3^{*}}$, IMAN TALAAT $^{1,3^{*}}$, ARYA VINODNADAT $^{3}$, AZZAM MAGHAZACHI $^{1,3}$, \\ SALAH ABUSNANA ${ }^{1,2}$, KARI SYRJÄNEN $^{4 \#}$ and RIYAD BENDARDAF ${ }^{1,2 \#}$ \\ ${ }^{1}$ College of Medicine, University of Sharjah, Sharjah, United Arab Emirates; \\ ${ }^{2}$ University Hospital Sharjah, Sharjah, United Arab Emirates; \\ ${ }^{3}$ Sharjah Institute of Medical Research, University of Sharjah, Sharjah, United Arab Emirates; \\ ${ }^{4}$ Department of Clinical Research, Helsinki, Finland
}

\begin{abstract}
Background: Insulin-like growth factor 1 receptor (IGFIR) activation triggers multiple signaling pathways involved in proliferation and anti-apoptosis in breast cancer $(B C)$. Materials and Methods: Immunohistochemistry for IGF1R was performed on 50 BC cases; expression was assessed for staining intensity and localization pattern (mixed, membranous, and cytoplasmic) which was correlated to hormone receptor status. Results: Of estrogen receptorpositive $\left(E R^{+}\right)$cases, $97.2 \%$ were $I_{G F 1 R^{+}}(48.6 \%$ mixed, $43.2 \%$ membranous, and $5.4 \%$ cytoplasmic pattern) compared to $\mathrm{ER}^{-}$cases $(38.5 \%, 7.7 \%$ and $30.8 \%$, respectively) ( $p=0.003)$. In progesterone receptor-positive $\left(P^{+}\right)$cases, $97.2 \%$ were IGFIR ${ }^{+},(47.2 \%, 41.7 \%$ and $8.3 \%$, respectively) compared to $P R^{-}$ones $(42.9 \%, 14.3 \%$ and $21.4 \%$, respectively) ( $p=0.036)$. For human epidermal growth factor receptor 2-negative $\left(\mathrm{HER2}^{-}\right)$cases, $88.8 \%$ were $\operatorname{IGF}_{1 R^{+}}\left(44.4 \%, 8.3 \%\right.$ and $36.1 \%$, respectively). All HER2 ${ }^{+}$ cases were $\operatorname{IGF}_{1 R^{+}}(71.4 \%, 7.1 \%$ and $21.4 \%$, respectively) $(p=0.015)$. In conclusion, hormone receptor-positive HER2cases showed membranous and mixed IGFIR localization. However, hormone receptor-negative and $H E R 2^{+}$showed
\end{abstract}

This article is freely accessible online.

*These Authors contributed equally to this study. \#These Authors share equal senior co-authorship.

Correspondence to: Dr Noura Alkhayyal, College of Medicine and Sharjah Institute of Medical Research, University of Sharjah, Sharjah, P.O. Box 27272, UAE. E-mail: doctornoura@gmail.com; Dr Iman Talaat, College of Medicine and Sharjah Institute of Medical Research, University of Sharjah, Sharjah, P.O. Box 27272, UAE. E-mail: italaat@sharjah.ac.ae

Key Words: Breast cancer, molecular subtypes, immunohistochemistry, IGF1R. cytoplasmic or diminished IGFIR expression. Conclusion: These luminal subtypes may benefit from targeted IGFR therapy in the future.

According to global cancer observatory statistic of 2018, breast cancer (BC) incidence is estimated to be around 2.1 million, which accounts for $11.6 \%$ of the total cancer incidence. Moreover, in females, BC ranks as the fifth leading cause of death (1). However, for the United Arab Emirates, $\mathrm{BC}$ is the most common cancer in females at $21 \%$ (2).

$\mathrm{BC}$ can be categorized into four distinct molecular subtypes, namely luminal A, luminal B, human epidermal growth factor receptor 2 (HER2)-overexpression and triple negative. Being able to distinguish between these different molecular subtypes helps in determining prognostic and predictive variables.

The insulin-like growth factor 1 (IGF1) receptor family is comprised of two IGF1 ligands (IGF1 and IGF2), six IGFbinding proteins (IGFBPs) that modulate receptor activity, IGFBP proteases, IGFBP-related protein and the transmembrane IGF receptor tyrosine kinase. The latter, is subdivided into IGF1R, a mitogen expressed on many cells all over the body; and IGF2R, which is structurally unrelated to IGF1R (3-5).

IGF1 is a single-chain polypeptide that is produced by the liver upon growth hormone stimulation. It has an essential physiological role in promoting cell growth, proliferation and differentiation, as well as mammary cell formation and development $(4,6)$. In addition to its involvement in endocrine, paracrine and autocrine signaling, it has a significant role in regulating fetal, neonatal and postnatal development (7).

Moreover, IGF1 involvement in pathophysiological conditions proved to be significant in different types of tumor, including breast cancer, ovarian cancer, and hepatocellular carcinoma, where it was found to reduce chemotherapeutic efficacy and increase tumorigenesis $(4,5,8,9)$. 
Binding of IGF1 to IGF1R triggers different downstream signaling pathways that stimulate proliferation and antiapoptotic processes (3). Yet it was found by a different research groups that the presence of IGF1R in cancer cells is a marker of cancer cell stemness (10).

The increase of IGF1R in BC cells was found to be due to an increase in IGF1 that is regulated by estradiol through synergistically stimulating cancer cell proliferation and suppressing several tumor-suppressor genes (11). Whereas it has been shown that there is a cross talk between estrogen receptor positivity $\left(\mathrm{ER}^{+}\right)$and IGF1R expression owing to up-regulation of $I G F I R$ transcription through activating ER complexes (12).

$\mathrm{BC}$ has been extensively studied and many reported molecular targets have been discovered, yet their relevance to clinical practice has not yet been evaluated and is still enigmatic.

In this study, we examined the expression of IGF1R in relation to different molecular subtypes of $\mathrm{BC}$ and the clinicopathological features in patients with locally advanced BC at University Hospital Sharjah (UHS) in the UAE.

\section{Materials and Methods}

Out of 61 patients diagnosed with primary BC, 11 were excluded from the study due to lack of patient data or specimens. Cases included in the study comprised 50 cases diagnosed with invasive BC which were surgically treated at Sharjah Breast Care Centre, UHS between May 2013 and March 2019. For all patients, formalin-fixed paraffin-embedded (FFPE) tumor blocks were available with complete clinicopathological and immunohistochemistry (IHC) data. The present work was approved by UHS Ethical and Research Committee (Ref. No.: UHSHERCYTOPLASMIC01-28012019). The study was conducted according to the principles of the Declaration of Helsinki. As this study was retrospectively conducted on FFPE blocks, the need for consent was waved by the Ethical Committee.

Clinical characteristics of the patients. The key demographic data of the patients and the clinicopathological characteristics of their tumors are presented in Table I. The mean age of the patients at the time of diagnosis was 52 years (range $=30-88$ years).

Histopathological examination. FFPE BC samples were cut into 5- $\mu \mathrm{m}-$ thick sections and stained by hematoxylin and eosin, followed by microscopic examination by an experienced histopathologist (IT) to assess histological type according to the 2012 WHO classification of breast tumors (13), histological grade according to Nottingham grading system (14), lymphovascular invasion (15) and the in situ (IS) component. Nodal status and extra-nodal extension were also evaluated. Disease was classified into four molecular subtypes: Luminal A, luminal B (HER2-/HER2 ${ }^{+}$), HER2-overexpressing and triple-negative (Table I). A cut-off value of $14 \%$ was used for Ki67 assessment.

IHC methods. Manual immunostaining for IGF1R was performed on 5- $\mu$ m-thick sections. In brief, FFPE sections were deparaffinized in xylene, rehydrated in graded alcohol, immersed in $0.01 \mathrm{M}$ citrate buffer ( $\mathrm{pH} 6.0$ ), heated in a domestic microwave oven at full power
Table I. Clinicopathological characteristics of the patients and their tumors $(n=50)$.

\begin{tabular}{llc}
\hline Patient characteristics & & Value \\
\hline Age, years & Mean (range) & $52(30-88)$ \\
BMI, kg/m ${ }^{2}$ & Mean (range) & $30.5(19.7-42.8)$ \\
Tumor size (cm) & Mean (range) & $3.1(0.6-10.5)$ \\
Tumor location & Left & $27(54 \%)$ \\
& Right & $23(46 \%)$ \\
TNM staging** & 1 & $19(38 \%)$ \\
& 2 & $21(42 \%)$ \\
& 3 & $6(12 \%)$ \\
Histological grade & 4 & $3(6 \%)$ \\
& IDC & $39(78 \%)$ \\
& ILC & $5(10 \%)$ \\
Nottingham grade & Medullary & $4(8 \%)$ \\
& Mixed & $2(4 \%)$ \\
& 1 & $6(12 \%)$ \\
& 2 & $20(40 \%)$ \\
Molecular subtype & 3 & $24(48 \%)$ \\
& DCIS & $28(56 \%)$ \\
& Luminal A & $12(24 \%)$ \\
& Luminal B & $14(28 \%)$ \\
Lymphovascular invasion & Triple-positive & $12(24 \%)$ \\
& PER2-overexpressing & $2(4 \%)$ \\
& Nesitive & $10(20 \%)$ \\
& Negative & $22(44 \%)$ \\
& Positive & $28(56 \%)$ \\
& Negative & $14(28 \%)$ \\
& & $36(72 \%)$ \\
\hline
\end{tabular}

DCIS: Ductal carcinoma in situ; HER2: human epidermal growth factor receptor 2; IDC: invasive ductal carcinoma; ILC: invasive lobular carcinoma; LCIS: lobular carcinoma in situ; TNM: tumor; node; metastasis. **Staging was recorded for 49 cases and the remaining case had no residual tumor after tumor resection subsequent to neoadjuvant management.

for $2 \times 5$ minutes and left in buffer to cool at room temperature. The sections were then incubated in $0.3 \%$ hydrogen peroxide for 20 minutes to block endogenous peroxidase activity. Incubation with the primary antibody (anti-IGF1R; Cell Signaling Technology, Inc., Boston, MA, USA) at concentration of 1:400 diluted in 1\% bovine serum albumin/tris-buffered saline was carried out overnight in a humid chamber at $4^{\circ} \mathrm{C}$ according to the manufacturer's instructions. The following day, the slides were washed and incubated first with biotinylated secondary antibody (SignalStain ${ }^{\circledR}$ Boost IHC Detection Reagent; Cell Signaling Technology) for $30 \mathrm{~min}$ at $20^{\circ} \mathrm{C}$, then with avidin-biotin-peroxidase complex for $30 \mathrm{~min}$ at $20^{\circ} \mathrm{C}$ (Vectastain $\mathrm{ABC}$ kit; Abcam, Cambridge, UK). For visualization, peroxidase/DAB DAKO Real ENVision detection system (DAKO, Glostrup, Denmark) was used, following the manufacturer's instructions. A negative control, by omitting the primary antibody, was included in each run, and a breast section that had been previously identified to express IGF1R was used as positive control.

Assessment of immunostaining. IGF1R expression was evaluated by two independent observers (NA, IT), blinded to the clinicopathological characteristics, using an Olympus microscope (BX51; Olympus, Tokyo, Japan). All discordant cases were resolved within consensus 
Table II. The pattern of expression of insulin-like growth factor 1 (IGF1R) as related to clinicopathological characteristics $(n=50)$.

\begin{tabular}{|c|c|c|c|c|c|c|}
\hline & & \multicolumn{5}{|c|}{ IGF1R expression pattern, n (\%) } \\
\hline & & Negative & Membranous & Cytoplasmic & Mixed & $p$-Value \\
\hline \multirow[t]{5}{*}{ Molecular subtype } & Luminal A & $1(8.3)$ & $7(58.3)$ & 0 & $4(33.3)$ & 0.002 \\
\hline & Luminal B & 0 & $8(57.1)$ & 0 & $6(42.9)$ & \\
\hline & Triple-positive & 0 & $1(8.3)$ & $3(25)$ & $8(66.7)$ & \\
\hline & HER2-overexpressing & 0 & 0 & 0 & $2(100)$ & \\
\hline & Triple-negative & $3(30)$ & $1(10)$ & $3(30)$ & $3(30)$ & \\
\hline \multirow[t]{3}{*}{ DCIS } & Absent & $4(21.1)$ & $7(36.8)$ & 0 & $8(42.1)$ & 0.05 \\
\hline & Present & 0 & $9(33.3)$ & $6(22.2)$ & $12(44.4)$ & \\
\hline & LCIS & 0 & $1(25)$ & 0 & $3(75)$ & \\
\hline \multirow[t]{3}{*}{ Nottingham grade } & 1 & 0 & $3(50)$ & $1(16.7)$ & $2(33.3)$ & 0.246 \\
\hline & 2 & $1(5)$ & $8(40)$ & 0 & $11(55)$ & \\
\hline & 3 & $3(12.5)$ & $6(25)$ & $5(20.8)$ & $10(41.7)$ & \\
\hline \multirow[t]{2}{*}{ Axillary nodal status } & Absent & $2(9.1)$ & $7(31.8)$ & $4(18.2)$ & 9 (40.9) & 0.704 \\
\hline & Present & $2(7.1)$ & $10(35.7)$ & $2(7.1)$ & $14(50)$ & \\
\hline
\end{tabular}

DCIS: Ductal carcinoma in situ; HER2: human epidermal growth factor receptor 2; LCIS lobular carcinoma in situ. Significant $p$-values are shown in bold.

Table III. The pattern of insulin growth factor 1 receptor (IGF1R) expression as related to other markers.

\begin{tabular}{|c|c|c|c|c|c|c|}
\hline & & \multicolumn{5}{|c|}{ IGF1R expression pattern, n (\%) } \\
\hline & & Negative & Membranous & Cytoplasmic & Mixed & $p$-Value \\
\hline \multirow[t]{2}{*}{ Estrogen receptor } & Negative & $3(23.1)$ & $1(7.7)$ & $4(30.8)$ & $5(38.5)$ & 0.003 \\
\hline & Positive & $1(2.7)$ & $16(43.2)$ & $2(5.4)$ & 18 (48.6) & \\
\hline \multirow[t]{2}{*}{ Progesterone receptor } & Negative & $3(21.4)$ & $2(14.3)$ & $3(21.4)$ & $6(42.9)$ & $\mathbf{0 . 0 3 6}$ \\
\hline & Positive & $1(2.8)$ & 15 (41.7) & $3(8.3)$ & $17(47.2)$ & \\
\hline \multirow[t]{2}{*}{ HER2 } & Negative & $4(11.1)$ & $16(44.4)$ & $3(8.3)$ & $13(36.1)$ & 0.015 \\
\hline & Positive & 0 & $1(7.1)$ & $3(21.4)$ & $10(71.4)$ & \\
\hline \multirow[t]{2}{*}{ Ki67 } & Negative & $1(6.7)$ & $8(53.3)$ & 0 & $6(40)$ & 0.157 \\
\hline & Positive & $3(8.6)$ & $9(25.7)$ & $6(17.1)$ & $17(48.6)$ & \\
\hline
\end{tabular}

HER2: human epidermal growth factor receptor 2; Ki67 cut-off=14\%. Significant $p$-values are shown in bold.

meetings. Only the infiltrating component of the neoplasm was evaluated. For the evaluation of IGF1R protein, a semiquantitative approach was used based on staining intensity (SI) and percentage of positively stained cells (PP) to create the immunoreactive score (IRS) as follows: IRS=SI $\times \mathrm{PP}$, for each sample, as previously described (16). The intensity was scored as follows: 0: No staining, 1: weakly positive, 2 : moderately positive and 3 : strongly positive. The scoring of the staining pattern was based on the percentage of positively stained cells: $0: 0 \%, 1: 0-9 \%, 2: 10-49 \%$ and $3: 50-100 \%$. The IRS score thus ranged from 0 to 9 , designated as negative for a score of 0 to 3 , and positive for a score of 4 to 9 . The localization of staining for each protein was also indicated as membranous, cytoplasmic or mixed.

Statistical analysis. IGF1R expression was statistically tested for correlation to all clinical variables retrieved, including the grade, stage, presence or absence of ductal carcinoma in situ and molecular subtypes.

Statistical analyses were performed using the SPSS ${ }^{\circledR}$ (version 25.0.0.2; IBM, Armonk, NY, USA) and STATA (STATA/SE 15.1;
Stata Corp., Houston, TX, USA) software packages. Frequency tables were analyzed using the chi-square test, with likelihood ratio or Fisher's exact test to assess the significance of the correlation between categorical variables. Differences in the means of continuous variables were analyzed using non-parametric tests (Mann-Whitney or Kruskal-Wallis tests) for two and multiple independent samples, respectively. Analysis of variance was only used for deriving the mean values (with $95 \%$ confidence intervaI) of each stratum. In all tests, values of $p<0.05$ were regarded as statistically significant.

\section{Results}

Out of 50 BC cases, 39 (78\%) patients were diagnosed as having invasive ductal carcinoma with the following molecular subtypes: 10 (25.6\%) luminal A, $12(30.8 \%)$ luminal B/HER2 ${ }^{-}, 10$ (25.6\%) luminal B/HER2 ${ }^{+}$(triple- 
Table IV. The pattern of insulin-like growth factor 1 (IGF1R) staining intensity as related to hormone receptor status in patients with breast cancer $(n=50)$.

\begin{tabular}{|c|c|c|c|c|c|c|}
\hline & & \multicolumn{5}{|c|}{ IGF1R staining intensity, $\mathrm{n}(\%)$} \\
\hline & & Negative & Weak & Moderate & Strong & $p$-Value \\
\hline \multirow[t]{2}{*}{ Estrogen receptor } & Negative & $3(23.1)$ & $1(7.7)$ & $(38.5)$ & $5(30.8)$ & 0.108 \\
\hline & Positive & $1(2.7)$ & $3(8.1)$ & $13(35.1)$ & $20(54.1)$ & \\
\hline \multirow[t]{2}{*}{ Progesterone receptor } & Negative & $3(23.1)$ & $1(7.7)$ & $4(28.6)$ & $6(42.9)$ & 0.219 \\
\hline & Positive & $1(2.7)$ & $3(8.1)$ & $14(38.9)$ & $18(50)$ & \\
\hline \multirow[t]{2}{*}{ HER 2} & Negative & $4(11.1)$ & $2(5.6)$ & $12(33.3)$ & $18(50)$ & 0.461 \\
\hline & Positive & 0 & $2(14.3)$ & $6(42.9)$ & $6(42.9)$ & \\
\hline
\end{tabular}

HER2: Human epidermal growth factor receptor 2.

positive), one (2.6\%) HER2-overexpressing and six (15.4\%) were triple-negative. Five (10\%) patients were reported as having invasive lobular carcinoma revealing the following molecular subtypes: two $(40 \%)$ luminal A, one $(20 \%)$ luminal B/HER2 ${ }^{-}$, one (20\%) triple-positive, and one (20\%) with HER2 overexpression. The four (8\%) cases diagnosed as medullary carcinoma were found to be triple-negative. The remaining two (4\%) cases diagnosed as mixed invasive ductal carcinoma and invasive lobular carcinoma were classified as follows: one (50\%) as luminal B/HER2 ${ }^{-}$and the other (50\%) as triple-positive (Table I).

The majority of cases were grade 2 and 3, with $80 \%$ of cases displaying histological features of grade 3 (Table I). Moreover, our study showed significant correlation of histological grading with different molecular subtypes. Grade I showed $50 \%$ of luminal A and only $16 \%$ of triple-negative subtype. Whereas grade III reported in only $4 \%$ of luminal A compared to $33 \%$ of triple-negative subtype. $(p=0.004)$. Ductal carcinoma in situ was detected in 27 patients and was related to IGF1R expression, with 12 mixed cases and nine membranous. Nevertheless, all six cases expressing only cytoplasmic IGF1R were ductal carcinoma in situ $(p=0.05)$ Table II.

$\mathrm{ER}^{+}$was significantly correlated with IGF1R membranous and mixed patterns. Out of $37 \mathrm{ER}^{+}$cases, a single case was negative for IGF1R staining. On the other hand, absence of ER expression was significantly correlated with the cytoplasmic and mixed IGF1R staining patterns $(p=0.003)$.

PR expression was found in 36 cases. Negative IGF1R staining was found in only one $\mathrm{PR}^{+}$case, whereas $\mathrm{PR}$ positivity was significantly correlated with the membranous and mixed patterns of IGF1R staining. On the other hand, $\mathrm{PR}^{-}$cases less frequently displayed the membranous pattern ( $p=0.036)$ Table III.

Altogether, 36 cases were HER2 ${ }^{-}$, the majority showing membranous and mixed pattern of IGF1R staining. On the other hand, HER $2^{+}$cases mostly had cytoplasmic and mixed staining patterns $(p=0.015)$ Table III.
Luminal $\mathrm{A}$ and luminal $\mathrm{B} / \mathrm{HER} 2^{-}$, the least aggressive molecular subtypes of $\mathrm{BC}$, demonstrated the membranous and mixed patterns of IGF1R expression. Luminal B/HER2 ${ }^{+}$ subtype showed less membranous staining and more cytoplasmic and mixed IGF1R expression. Two cases diagnosed as HER2-overexpressing had only the mixed pattern of staining. Furthermore, in triple-negative cases, IGF1R localization was more of a cytoplasmic and mixed pattern Table III.

For Ki67 assessment, a cut-off value of $14 \%$ was used and compared to IGF1R localization and intensity, with no significant differences being found (Table III). IGF1R staining intensity was not found to be significantly correlated to HR and HER2 expression or other variables (Table IV).

\section{Discussion}

Defining the intrinsic BC subtypes is an essential component for disease characterization. Patients exhibiting positive expression of ER and PR show a better clinical outcome, and a more favorable response to hormonal therapy. In contrast, HER2 overexpression is a prognostic indicator reflecting aggressive tumor behavior, similar to triple-negative cases $(17,18)$.

Thus, studying different molecular prognostic and predictive markers will help in categorizing the patients with BC into low- and high-risk groups and might predict the likelihood of developing metastasis or disease recurrence.

IGF1R was chosen for the assessment in this study due to its role in tumorigenesis, and anti-apoptotic effect in different tumor settings. A positive correlation was found between $\mathrm{ER}^{+}$and IGF1R expression in BC tumors; nevertheless, loss of IGF1R expression was previously associated with tumor progression (19-23).

The results of the current study revealed significant correlation between $\mathrm{ER}^{+}$and IGF1R expression, $97.2 \%$ of $\mathrm{ER}^{+}$cases also being positive for IGF1R expression. As to the distinct staining patterns, the present results showed that 

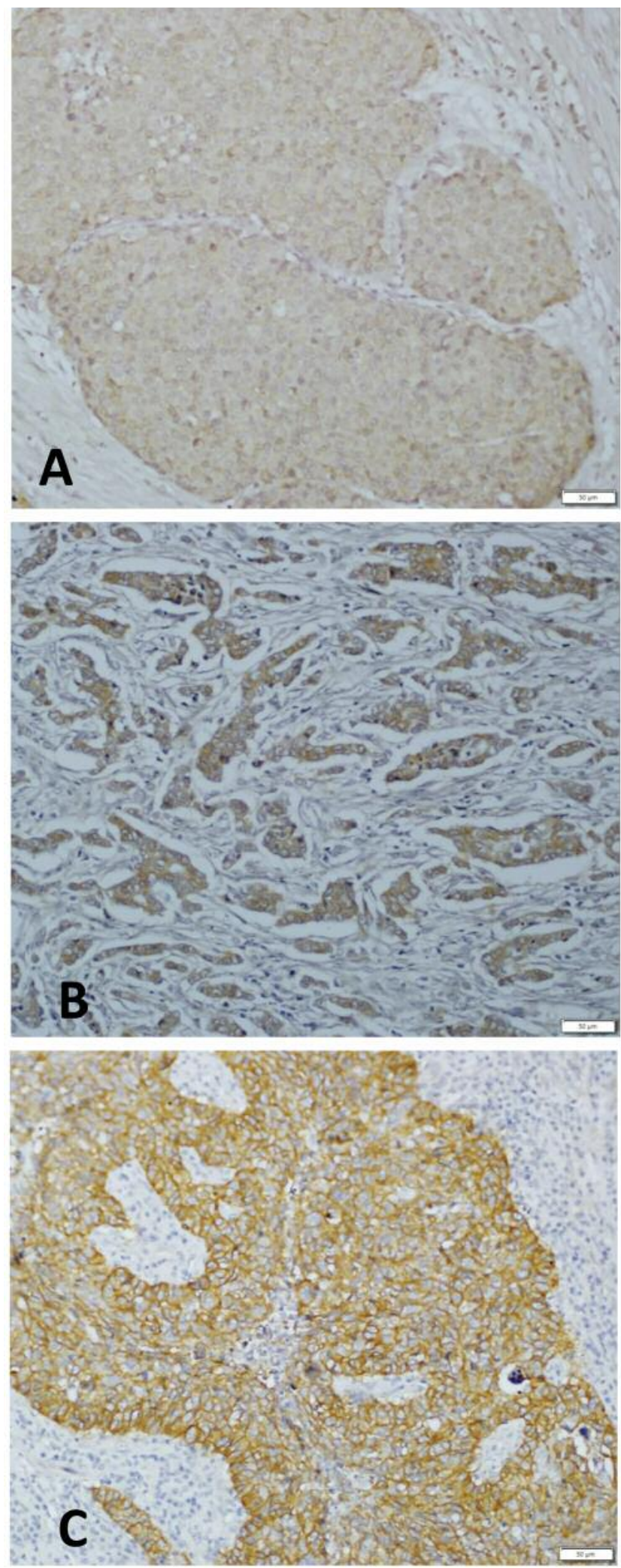

Figure 1. Representative sections of immunohistochemical staining for insulin-like growth factor 1 receptor showing weak $(A)$, moderate $(B)$ and strong staining $(C)$ in breast cancer (magnification, $\times 20$ ).
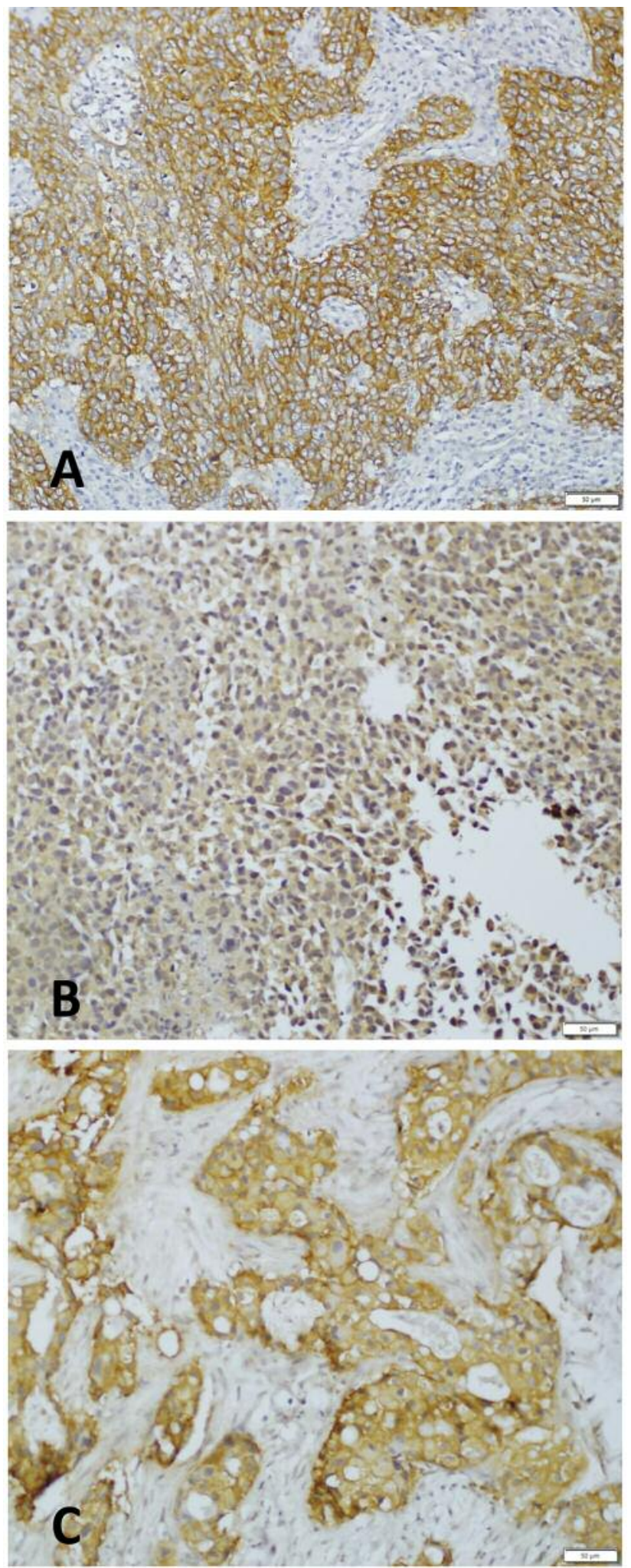

Figure 2. Localization of insulin-like growth factor 1 receptor in breast cancer. Representative sections showing membranous (A), cytoplasmic (B) and mixed $(C)$ patterns of localization of reaction to monoclonal antibody against insulin-like growth factor 1 receptor (magnification, $\times 20$ ). 
$\mathrm{ER}^{+}$cases had mixed and membranous IGF1R, which is consistent with a previously conducted study on IGF1R status in patients with $\mathrm{BC}$ which showed significant correlation between $\mathrm{ER}^{+}$status and IGF1R expression (12).

For PR expression, 97\% of $\mathrm{PR}^{+}$cases had IGF1R expression with the highest number of cases displaying mixed and membranous patterns of IGF1R expression. In $\mathrm{PR}^{-}$cases, the membranous pattern was detected in only two cases.

In a study on normal breast tissues assessing the risk of developing $\mathrm{BC}$, it was found that in $\mathrm{ER}^{+}$and $\mathrm{PR}^{+}$cases, IGF1R expression was of the membranous type. Moreover, patients with only the cytoplasmic pattern of IGF1R expression were more likely to develop $\mathrm{BC}$, with a risk of 15 times higher than patients with negative IGF1R expression (6); our finding that aggressiveness of the disease is associated with a cytoplasmic and mixed pattern of IGF1R expression supports this association.

A cytoplasmic expression pattern is proposed to be due to receptor internalization of IGF1R that results from membranous receptor activation. The latter is supported by membranous staining typical in cells cultured in the absence of IGF ligand, which, however, is lost following stimulation with ligand (6).

According to the UniProt Database, epigenetic modifications are involved in IGF1R activation. It has been observed that receptor internalization and proteasomal degradation are the result of polyubiquitination of receptor lysine residues that is facilitated by receptor phosphorylation $(6,24)$. In addition, it was shown by Christopoulos et al. that high levels of IGF1 circulating endogenously in patients with $\mathrm{BC}$ was a sign of poor prognosis. In addition, there also seems to be an association between ER positivity and IGF1 ligand, higher levels of IGF1R being detected in patients with early BC (4).

HER2 is another important marker contributing to the classification of BC molecular subtypes. In the present series, $88.8 \%$ of HER2 ${ }^{-}$cases expressed IGF1R, with the highest expression being of the membranous pattern. Interestingly, only one HER $2^{+}$case had the membranous pattern. It has been shown that in HER2 ${ }^{-}$cases positive for hormone receptor, a better clinical outcome was observed for patients with positive IGF1R expression. Moreover, a more favorable prognosis was shown in those with luminal B subtype expressing IGF1R as compared with the cases showing HER2 overexpression (4).

Ki67 is a proliferation marker, usually assessed against a defined cutoff value, and expressed in highly proliferating cells (25-27). In the present series, Ki67 in relation to IGF1R localization and staining intensity did not show any significant correlation. However, in a single patient where HER2 was overexpressed and IGF1R localization was membranous, Ki67 activity was low. This might imply that less aggressive disease is associated with membranous localization of IGF1R on BC cells.

A crosstalk between ER, HER2 and IGF1R has been described, in which IGF1 is proposed to regulate ER activity.
It was found that a combined treatment with selective ER modulator and IGF1R inhibitor was significantly more effective than using a single-agent treatment on different $\mathrm{ER}^{+}$and HER2 ${ }^{+/-}$cell lines with variable IGF1R intensity. This effect was due to the induction of cell-cycle arrest (11).

\section{Conclusion}

In this preliminary study, we analyzed IGF1R localization in patients with BC stratified by different molecular subtypes. As a next step, IGF1R localization needs to be correlated with disease outcomes in longitudinal follow-up studies. A larger sample size is likely to increase the statistical significance of some interesting correlations of IGF1R with the clinicopathological variables that remained of borderline significance in the present study due to the restricted cohort size.

\section{Conflicts of Interest}

The Authors declare that they have no conflicts of interests. The present work was not funded.

\section{Authors' Contributions}

NA selected patient specimens, analyzed and interpreted the patient data, and wrote the article. IT performed the histological examination and IHC interpretation of the specimens, analyzed and interpreted the patient data, participated in writing the article. AV performed the sectioning of the specimens, hematoxylin and eosin and Immunohistochemistry staining. AM read and approved the final article. SA read and approved the final article. KS performed the statistical analysis of the study, revised the draft article and approved the final version. RB selected patient specimens, analyzed and interpreted the patient data, revised the draft article and approved the final version. The datasets used and analyzed during the current study are available from the corresponding Author on reasonable request.

\section{Acknowledgements}

The Authors would like to acknowledge Mr. Edward Abueme, senior histopathology technologist in University Hospital Sharjah laboratory for retrieving the FFPE blocks and preparing the unstained slides of the specimens.

\section{References}

1 World Health Organization, The Global Cancer Observatory (GCO). Available at: http://gco.iarc.fr/(Last accessed on 12 March 2020)

2 Ministry of Health and Prevention. National Cancer Registry Annual Report 2015. Available at: https://www.mohap.gov.ae/

3 Kang HS, Ahn SH, Mishra SK, Hong KM, Lee ES, Shin KH, Ro J, Lee KS and Kim MK: Association of polymorphisms and haplotypes in the insulin-like growth factor 1 receptor (IGF1R) gene with the risk of breast cancer in Korean women. PLoS One 9(1): e84532, 2014. PMID: 24392142. DOI: 10.1371/journal.pone. 0084532 
4 Christopoulos PF, Msaouel P and Koutsilieris M: The role of the insulin-like growth factor-1 system in breast cancer. Mol Cancer 14: 43, 2015. PMID: 25743390. DOI: 10.1186/s12943-015-0291-7

5 Liefers-Visser JAL, Meijering RAM, Reyners AKL, van der Zee AGJ and de Jong S: IGF system targeted therapy: Therapeutic opportunities for ovarian cancer. Cancer Treat Rev 60: 90-99, 2017. PMID: 28934637. DOI: 10.1016/j.ctrv.2017.08.012

6 Tamimi RM, Colditz GA, Wang Y, Collins LC, Hu R, Rosner B, Irie HY, Connolly JL and Schnitt SJ: Expression of IGF1R in normal breast tissue and subsequent risk of breast cancer. Breast Cancer Res Treat 128(1): 243-250, 2011. PMID: 21197570. DOI:10.1007/s 10549-010-1313-1

7 Allard JB and Duan C: IGF-binding proteins: Why do they exist and why are there so many? Front Endocrinol 9: 117, 2018 PMID: 29686648. DOI: 10.3389/fendo.2018.00117

8 Ou DL, Lee BS, Lin LI, Liou JY, Liao SC, Hsu C and Cheng AL: Vertical blockade of the IGFR-PI3K/AKT/mTOR pathway for the treatment of hepatocellular carcinoma: The role of survivin. Mol Cancer 13: 2, 2014. PMID: 24387108. DOI: 10.1186/1476-459813-2

9 Schmidt S, Monk JM, Robinson LE and Mourtzakis M: The integrative role of leptin, oestrogen and the insulin family in obesity-associated breast cancer: Potential effects of exercise. Obes Rev 16(6): 473-487, 2015. PMID: 25875578. DOI: 10.1111/obr.12281

10 Takada Y, Takada YK and Fujita M: Crosstalk between insulinlike growth factor (IGF) receptor and integrins through direct integrin binding to IGF1. Cytokine Growth Factor Rev 34: 6772, 2017. PMID: 28190785. DOI: 10.1016/j.cytogfr.2017.01.003

11 McDermott MSJ, Canonici A, Ivers L, Browne BC, Madden SF, O'Brien NA, Crown J and O'Donovan N: Dual inhibition of IGF1R and ER enhances response to trastuzumab in HER2positive breast cancer cells. Int J Oncol 50(6): 2221-2228, 2017. PMID: 28498399. DOI: 10.3892/ijo.2017.3976

12 Gaben A, Sabbah M, Redeuilh G, Bedin M and Mester J: Ligandfree estrogen receptor activity complements IGF1R to induce the proliferation of the MCF-7 breast cancer cells. BMC Cancer 12: 291, 2012. PMID: 22799881. DOI: 10.1186/1471-2407-12-291

13 Lakhani SR (ed): WHO Classification of Tumours of the Breast. International Agency for Research on Cancer; 2012.

14 Elston CW and Ellis IO: Pathological prognostic factors in breast cancer. I: The value of histological grade in breast cancer: Experience from a large study with long-term follow-up. Histopathology 19(5): 403-410, 1991. PMID: 1757079. DOI 10.1111/j.1365-2559.1991.tb00229.x

15 Rosen PP: Tumor emboli in intramammary lymphatics in breast carcinoma: Pathologic criteria for diagnosis and clinical significance. Pathol Annu 18(Pt 2): 215-232, 1983. PMID: 6674861.

16 Diallo-Danebrock R, Ting E, Gluz O, Herr A, Mohrmann S, Geddert H, Rody A, Schaefer KL, Baldus SE, Hartmann A and Wild PJ: Protein expression profiling in high-risk breast cancer patients treated with high-dose or conventional dose-dense chemotherapy. Clinical Cancer Res 13(2): 488-497, 2007. PMID: 17255270. DOI: 10.1158/1078-0432.CCR-06-1842

17 Fragomeni SM, Sciallis A and Jeruss JS: Molecular subtypes and local-regional control of breast cancer. Surg Oncol Clin N Am 27(1): 95-120, 2018. PMID: 5715810. DOI: 10.1016/j.soc.2017.08.005

18 Wolff AC, Hammond MEH, Allison KH, Harvey BE, Mangu PB, Bartlett JMS, Bilous M, Ellis IO, Fitzgibbons P, Hanna W, Jenkins RB, Press MF, Spears PA, Vance GH, Viale G, McShane
L and Dowsett M: Human epidermal growth factor receptor 2 testing in breast cancer: American Society of Clinical Oncology/College of American Pathologists clinical practice guideline focused update. J Clin Oncol 36(20): 2105-2122, 2018. PMID: 29846122. DOI: 10.1200/JCO.2018.77.8738

19 Obr AE, Kumar S, Chang Y-J, Bulatowicz JJ, Barnes BJ, Birge RB, Lazzarino DA, Gallagher E, LeRoith D and Wood TL: Insulin-like growth factor receptor signaling in breast tumor epithelium protects cells from endoplasmic reticulum stress and regulates the tumor microenvironment. Breast Cancer Res 20(1): 138, 2018. PMID: 30458886. DOI: 10.1186/s13058-018-1063-2

20 Jones RA, Campbell CI, Gunther EJ, Chodosh LA, Petrik JJ, Khokha R and Moorehead RA: Transgenic overexpression of IGF-IR disrupts mammary ductal morphogenesis and induces tumor formation. Oncogene 26(11): 1636-1644, 2007. PMID: 16953219. DOI: 10.1038/sj.onc.1209955

21 Peiró G, Adrover E, Sánchez-Tejada L, Lerma E, Planelles M, Sánchez-Payá J, Aranda FI, Giner D and Gutiérrez-Aviñó FJ: Increased insulin-like growth factor-1 receptor mRNA expression predicts poor survival in immunophenotypes of early breast carcinoma. Modern Pathol 24(2): 201-208, 2011. PMID: 21057462. DOI: $10.1038 /$ modpathol.2010.191

22 Yerushalmi R, Gelmon KA, Leung S, Gao D, Cheang M, Pollak M, Turashvili G, Gilks BC and Kennecke H: Insulin-like growth factor receptor (IGF-1R) in breast cancer subtypes. Breast Cancer Res Treat 132(1): 131-142, 2012. PMID: 21574055. DOI: $10.1007 / \mathrm{s} 10549-011-1529-8$

23 Mountzios G, Aivazi D, Kostopoulos I, Kourea HP, Kouvatseas G, Timotheadou E, Zebekakis P, Efstratiou I, Gogas H, Vamvouka C, Chrisafi S, Stofas A, Pentheroudakis G, Koutras A, Galani E, Bafaloukos D and Fountzilas G: Differential expression of the insulin-like growth factor receptor among early breast cancer subtypes. PLoS One 9(3): e91407, 2014. PMID: 24637962. DOI: 10.1371/journal.pone.0091407

24 UniProtKB - P08069; (IGF1R_HUMAN). 2019, UniProt. Available at: https://www.uniprot.org/uniprot/P08069

25 Cheang MCU, Chia SK, Voduc D, Gao D, Leung S, Snider J, Watson M, Davies S, Bernard PS, Parker JS, Perou CM, Ellis MJ and Nielsen TO: Ki67 index, HER2 status, and prognosis of patients with luminal B breast cancer. J Natl Cancer Inst 101(10): 736-750, 2009. PMID: 19436038. DOI: 10.1093/jnci/djp082

26 Goldhirsch A, Wood WC, Coates AS, Gelber RD, Thürlimann B, Senn HJ and Panel Members: Strategies for subtypes-dealing with the diversity of breast cancer: Highlights of the St. Gallen International Expert Consensus on the primary therapy of early breast cancer 2011. Ann Oncol 22(8): 1736-1747, 2011. PMID: 21709140. DOI: 10.1093/annonc/mdr304

27 Oh H, Eliassen AH, Beck AH, Rosner B, Schnitt SJ, Collins LC, Connolly JL, Montaser-Kouhsari L, Willett WC and Tamimi RM: Breast cancer risk factors in relation to estrogen receptor, progesterone receptor, insulin-like growth factor-1 receptor, and Ki67 expression in normal breast tissue. NPJ Breast Cancer 3: 3939, 2017. PMID: 28979927. DOI: 10.1038/s41523-017-0041-7

Received February 1, 2020

Revised February 13, 2020

Accepted February 14, 2020 